colour-blindness, there is a still larger number of cases where no such eonsideration is extended to them, and where dismissal is necessarily followed by the greatest hardship, and often by absolute ruin.

5: The method of testing colour-blindness or any defect in vision must be improved-

(a) By being done by competent medical examiners.

(b) In a room specially set apart for this purpose, and fitted with artificial light of a standard which would supply equal illuminating power all the year round and obviate the varying and unsatisfactory results of tests, applied at one time in the strongest light of midsummer, and perhaps another during the fogs of midwinter.

I have almost finished. It is sixteen years since I first became interested in the subject of colour-blindness. That interest very soon gave way to anxiety and the keenest regret on recognising the fact that colour-blindness in the mercantile marine personnel was a double-edged sword, involving, if undiscovered, in the gravest danger, the sea-travelling community, while, if detected, entailing the destruction of the hopes, home, and career of the unfortunate possessor.

I have endeavoured to impress these two facts alike on the shipowners in the interest of their passengers and on the Board of Trade in the interest of the sailor. My efforts have been but partially successful. The Board of Trade still permit colour-blind and defective sighted boys and men to enter the sea profession; the shipowner-though he may not know it-still employs colour-blind and defective-sighted officers. I personally know of more than forty of such at sea to-day. Who are we that we should blame these unfortunate men? The Government that has permitted them to enter the sea profession, then destroyed their opportunity of becoming officers, casts them aside like clods and the men have to .choose between literal starvation and a return to the sea life. And, verily, we reap our reward. The main cause of the appalling loss of life at sea is collision. The main cause of collision is the want of a proper look-out. From year to year the nation is stirred to its very depths by some fearful catastrophe by which in a few moments the sea entombs hundreds of precious lives. Are they the victims of an unfortunate, who, at a critical moment, failed to discrimate between a red and a green light?

Let those who would lightly say, "it is not possible," pause and listen to the following quotation taken verbatim from the Times, February 5th, 1889.

A terrible calamity occurred in the English Channel on Sunday night. During fine clear weather two vessels which had had each other in sight for at least a couple of miles came into collision and sank within fifteen minutes, leaving their crews struggling amid the wreckage in the sea. minutes, leaving their crews struggling amid the wreckage in the sea. Of forty-two men twenty-three went down, and all would inevitably have perished but for the presence of a tug on the scene. All inquiries respecting the cause of this disaster lead to the same conclusion that it was due to one of those astounding errors of judgment on the part of one or other of the navigators, which seems to defy all attempts at reasonable

Does anyone still think it unlikely? Then listen to one more quotation from the Times of August $20 t h, 1888$.

It is admitted that the vessels knew of one another's proximity for aeveral minutes before the one dashed into the other. The weather was not at fault, the sea was not unusually high, there was no fog at the crisis -each saw the other approaching in time to put a mile between them, and yet five minutes saw the whole tragedy played out and ro5 men and women have actually been sacrificed. But there ought to be some means of :abolishing disasters like this of Sable Island altogether. Here was neither recklessness nor calculated audacity, nor lethargy. All due -vigilance seems to have been exerted, and on both sides. But somebody, whether on board the Geisler or on the Thingvalle, must be responsible though probably no penalty can ever be exacted. The rule of the road at -sea itself needs to be brought to trial, if two well-found ocean steamer in ordinary Atlantic weather, with crews and officers reasonably on the Jook-out, can, either by its observance or non-observance, find themselves suddenly locked in a murderous embrace. The rule ought to be so simple and unmistakable as to render a collision in the circumstances of last Tuesday impossible. Controversies, of which our columns have frequently been the scene, prove that sailors, lawyers, and merchants have not as yet been perfectly successful in devising one adequately free from ambiyuities. The awful end of the Geisler is additional testimony to their igailure. The world has a right to demand of maritime experts rules on the subject of collisions which only blind men or madmen shall be able tho misunderstand or disobey.

The Times, in this last sentence, most unconsciously hit on the real cause of these terrible collisions, and just so long as men blind to colours-and therefore blind to every rule devised for safe navigation"by night-are tolerated under any circumstances in the mercantile marine, just so long may we expect to hear of these terrible disasters.

Of the many thousands of collisions that have taken place our mighty Board of Trade has never-no, not in a single case -has never instituted an inquiry into the eyesight of a surviving officer or look-out, but on the contrary has contemptuously declined to do so. Sailors, lawyers, and merchants have failed, while we, the ophthalmic section of the medical profession, have for nearly fifty years been crying in the wilderness.

CoRrigenduM.-The paper on Thyroid Extract in Lupus, published in the British Medical Journal of October 24th, p. I 200; was wrongly attributed to Dr. Barclay, of Wetheral. The author is Dr. John Barclay, of Banff.

\section{A CASE OF LEONTIASIS: OSSEA.}

BY JAMES YOUNG, M.D.

Medical Officer of Health, St. George's, Bristol.

THE term "leontiasis ossea," by which Virchow described a rare affection which has as its distinguishing patholongical feature a hyperostosis of the bones of the face and cranium, has been widely applied to express a variety of conditions of these parts. The most limited, and perhaps also the most generally recognised, as well as the most correct, application of this term is, however, to that condition in which the frontal and superior maxillary bones are alone involved, and

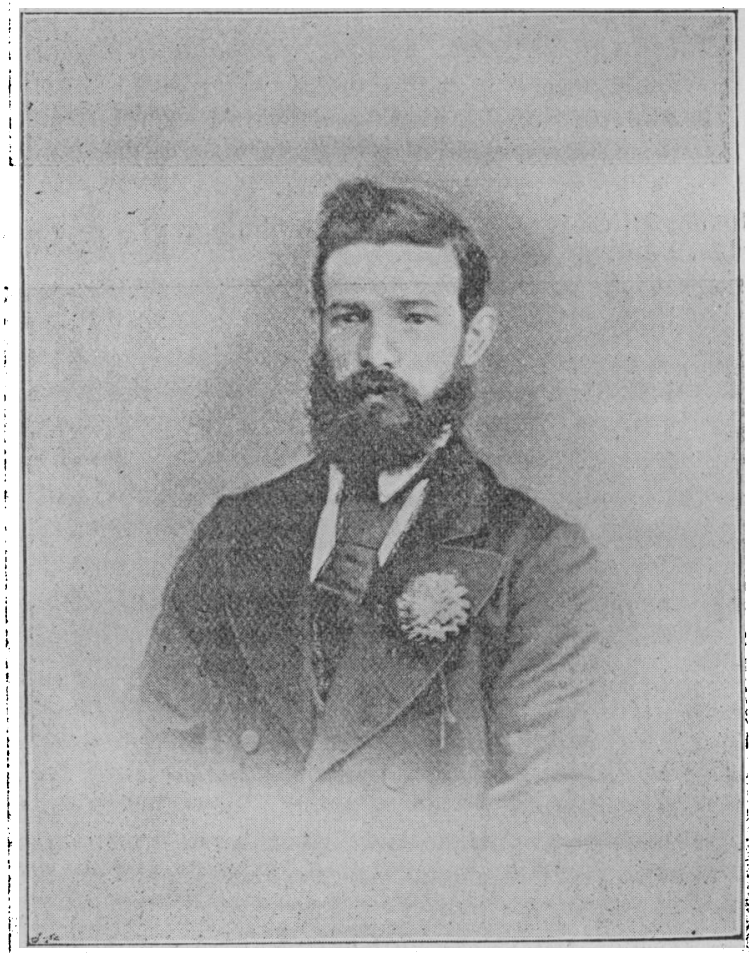

Fig 1.-From a photograph taken eighteen years ago.

these being implicated in the manner described by Virchow produce the deformity which has given the disease its name.

In the present case the term is used to describe a condition in which symmetrical prominent bosses of bone developed on the superior maxillæ, and to a less degree upon the frontal bones. The superior maxillæ were thickened generally, and there was also distinct prominence and thickening of the supraorbital ridge on each side, more marked perhaps on the right. As a result of the thickening of the bones in that region the orbital cavity had become diminished in size, producing the condition of exophthalmos and eetropion, which 
will be observed in the illustrations, the eyes being pushed forwards and outwards.

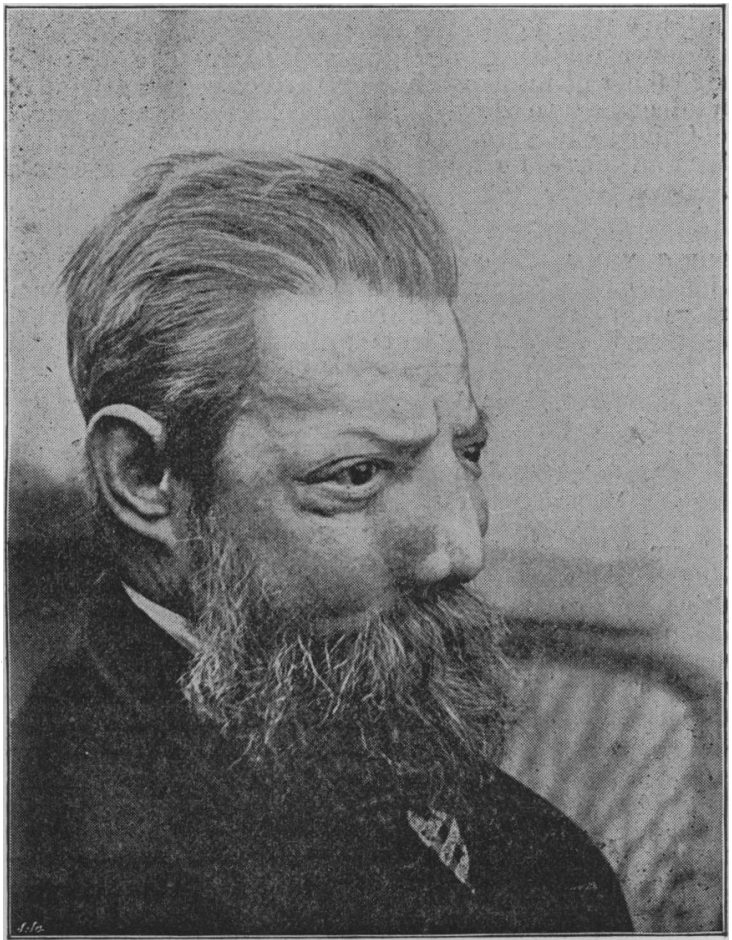

Fig. 2.-Side face.

The condition is well shown in the photographs reproduced in Figs. 2 and 3.

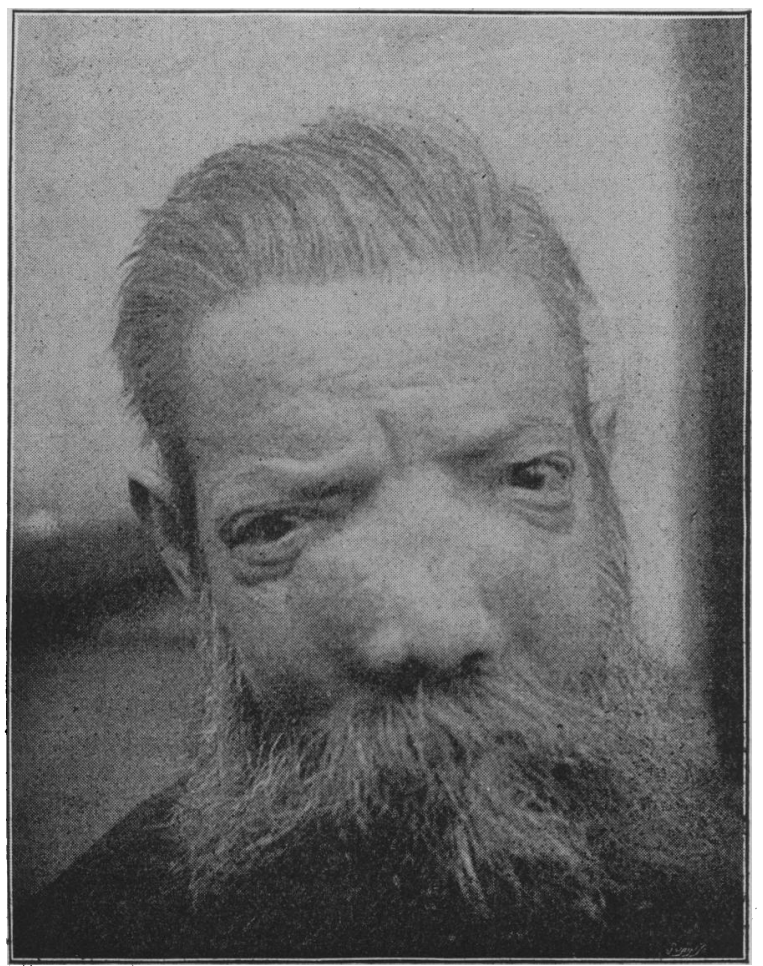

Fig. 3.-Full face.

The encroachment of the masses of bone upon the nasal cavity had so compressed the olfactory nerve as to destroy the sense of smell, and the nasal mucous membrane had lost its susceptibility to irritating substances, such as pepper, snuff, etc. Vision was weak, taste normal.

The patient did not complain of pain, but there was some tenderness over the protuberant masses on maxillæ. The soft parts were normal, except that the skin seemed thin over the maxillary bosses. The extremities were normal. In the few cases of this affection hitherto recorded the disease had begun to show itself in early life, and to progress with extreme slowness. In the present case the disease did not become apparent until about seven years ago, when the patient's wife first noticed a small swelling "about the size of a nut" on the left side of the face, over the superior maxilla. He was then 39 years of age, and a photograph in his wife's possession, taken some eighteen years ago (of which Fig. $I$ is a copy) shows no indication of the disease having commenced at that time at least. Neither the patient nor his friends could assign any cause for the onset of the disease. There is a history of an injury to the head from falling off a tramcar some six years ago, but this was at least a year after the enlargement of the bones of the face had made itself apparent to the patient's friends. The patient had been an inmate of Gloucester Lunatic Asylum on three different occasions: the first time in 1891 -two years after the nodular swelling was first observed; the last occasion in 1894, when he remained twelve months. He was then the subject of various delusions, and of hallucinations of sight and hearing. The family history is as follows: His father died at the age of 72 ; his mother at 70-both of senile diseases. One sister died in a lunatic asylum at the age of 30 . Three other sisters and one brother were alive and well. No other member of the family had ever shown any indications of the deformity from which the patient himself suffered.

The patient died quite suddenly on Mary 27th, 1896, at the age of 46 . He appeared to have a return of the delusions from which every now and again he suffered, and was engaged in driving a number of imaginary men out of his shop at about 4 o'clock in the morning, when he was suddenly seized with an attack of syncope, from which he died before medical aid could reach him.

Post-Mortem Examination.-The brain generally was soft, the dura mater slightly adherent along the superior longitudinal sinus. The base and nerves at entrance to foramina were normal; olfactory bulbs normal ; no appearance of hæmorrhage anywhere on surface or interior of brain. The sella turcica was normal in size, and there was no enlargement of the pituitary body. The vault of the skull was normal in thickness, and there was nothing unusual about the cerebral aspect of the base; no occlusion of foramina at base. The frontal sinuses and antrum were occluded, the orbital cavity diminished. The nasal cavity was filled up by encroachment of bosses of bone on each side. Right superior maxilla along its alveolar margin very considerably thickened. The bosses of bone protruding from maxillæ were on section found to be cancellous in structure, the skin ove them tense and thin. Within the chest the right lung was found to be adherent, the left normal; pericardium normal; heart very soft and flabby. Aorta markedly atheromatous, valves fenestrated; mitral valves also atheromatous; calcareous deposits chiefly confined to ventricular surface. Abdominal organs generally healthy, with exception of the kidneys, which were markedly granular and contracted; the capsule of the left was very adherent, and, on stripping, part of the kidney substance came away with it.

A Deputation of members of the Scottish Poor-Law Medical Officers' Association waited upon the Scottish Local Government Board in Edinburgh on October 2oth. Dr. Bruce, of Dingwall, Honorary President of the Association, introduced the deputation, and explained that the object of their visit was to ask the assistance or guidance of the Board in obtaining for them a similar tenure of office to that already possessed by their brethren in England and Ireland. After an interesting interview, which lasted over an hour, and a patient and sympathetic hearing from the Board, who promised to give the matter a cordial and full consideration, the deputation withdrew. 